\title{
CONTAÇÃO DE HISTÓRIAS: O MITO COMO FERRAMENTA DE APROXIMAÇÃO ENTRE A UNIVERSIDADE E POVOS TRADICIONAIS
}

\section{COUNTING STORIES: THE MYTH AS A TOOL TO APPROACH THE UNIVERSITY AND TRADITIONAL PEOPLES}

\author{
Wallace Gomes Ferreira de Souza* \\ Jessica Kallyne Arruda Silva** \\ Rosana de Medeiros Silva*** \\ Wagner Berto dos Santos Diniz ${ }^{* * * *}$
}

\section{RESUMO}

O projeto "A botija é nossa: contação de história e sociabilidade no Cariri paraibano" teve desenvolvimento de suas atividades nas três comunidades remanescentes de quilombo do Município de LivramentoPB (Areias de Verão, Sussurana e Vila Teimosa), com o objetivo de fomentar espaços de integração universidade/comunidade. Tais atividades extensionistas ampliam a compreensão de espaço formativo e contribuem na valorização dos sujeitos negros quilombolas. Leva como proposta metodológica a transdisciplinariedade entre as Ciências Humanas e Sociais e a área das linguagens. Neste sentido, a contação e o registro das histórias orais foram assumidas neste projeto como instrumentos metodológicos que possibilitam a percepção/experiência com as dinâmicas de organização desse grupo étnico. Com esta atividade, produzimos experiências formativas aos discentes do curso de Ciências Sociais, bem como para os sujeitos quilombolas, protagonistas dessa ação, aspecto que remete para o princípio da extensão: construir um espaço universitário integrado com as demandas dos sujeitos concretos.

Palavras chaves: histórias; comunidades; quilombolas; Cariri; transdiciplinaridade.

\section{ABSTRACT}

The project "The botija is ours: history and sociability in Cariri Paraíba" has developed its activities in the three remaining quilombo communities in the municipality of Livramento-PB (Sands of Summer, Sussurana and Vila Teimosa). It aims at fostering university / community integration spaces. Such extension

\footnotetext{
* Professor da Universidade Federal de Campina Grande (UFCG), PB - Brasil. E-mail: wallace.ferreiradesouza@gmail.com

** Aluna de graduação da Universidade Federal de Campina Grande (UFCG), PB - Brasil. E-mail: arrudajessica.21@gmail.com

*** Aluna de graduação da Universidade Federal de Campina Grande (UFCG), PB - Brasil. E-mail: zana.medeiros@hotmail.com 
activities broaden the understanding of formative space and contribute to the valorization of black quilombola individuals. Its methodological proposal is the transdisciplinary between Human and Social Sciences and the area of languages. In this sense, the oral stories are recorded and used as methodological tools that allow the perception / experience of the dynamics of organization of this ethnic group. With this activity, we produce formative experiences for the students of the Social Sciences course as well as for the quilombola subjects, protagonists of this action, aspect that refers to the principle of extension, to build a university space integrated with the demands of the concrete subjects

Keywords: stories; communities; quilombolas; Cariri; transdisciplinarity.

\section{Introduçáo}

O projeto "A botija é nossa: contação de história e relaçôes de sociabilidade no Cariri paraibano" está ligado ao Programa de Bolsa de Extensão - PROPEX/UFCG ${ }^{1}$, e traz um diferencial um tanto considerável que é a alusão à famosa botija², que seria um tesouro enterrado, deixado pelos mortos e entregue por estes, em sonho, aos vivos. Histórias que fazem parte da memória social das comunidades remanescentes de quilombo. A ideia foi pegar a expressão sem modificar seu sentido axiológico e trocar o que se tinha como conteúdo da botija, que estaria cheia de moedas de ouro e jóias preciosas. "A botija é nossa" está cheia de história, e essas memórias são a riqueza onde os costumes e crenças de um povo encontram perenidade.

A pesquisa tem como lócus de desenvolvimento de suas atividades três comunidades remanescentes de quilombo do Município de Livramento-PB (Areias de Verão, Sussurana e Vila Teimosa). Localizadas no município de Livramento, são as únicas até então reconhecidas pela Fundação Cultural Palmares-FCP, na região do Cariri paraibano. Desta forma, é de fundamental importância a construção de políticas de visibilidade e promoção de igualdade de oportunidade para os sujeitos quilombolas destas comunidades.

Desse modo, foi realizado um intenso trabalho de preparação, com oficinas de contação de histórias, teatro, leituras e também discussóes de textos tratando de questóes teóricas sobre memória, oralidade e as Ciências Sociais. Todo o trabalho girou em torno da consciência da ação pedagógica realizada durante as intervençóes. A diferença estava em não ter a necessidade de criar uma atmosfera táo idílica, e, sim, de fazer com que o realizado pudesse envolver a comunidade com algo que era dela, suas histórias.

O cenário montado na primeira intervenção favoreceu uma interação de costumes e práticas de diversas culturas. Vários tipos de manifestações populares foram realizados, como por exemplo, histórias narradas, apresentação de um grupo de capoeira e, posteriormente, a exibição de um grupo teatral, criando uma mística com as histórias retiradas de um livro da própria comunidade. $\mathrm{O}$ encerramento acontecera em um dos salóes da Escola Municipal Jeorgina Josefa de Souza, localizada na comunidade de Areias de Verão, ao som de forro pé de serra.

A segunda intervenção realizou-se na primeira metade do mês de dezembro de 2016. Foram distribuídos presentes para um público de 30 crianças, entre 5 e 10 anos de idade, em meio a uma encenação montada pelos membros do projeto "A botija é nossa". Nesse dia, participaram professores, o secretário de educação do município de Livramento, mães de alunos e membros das comunidades.

Todo o trabalho foi recompensado com o sucesso das duas intervençóes realizadas. Muitas foram as viagens até as comunidades quilombolas, reunióes com seus representantes, conversas isoladas com seus membros e visitas às suas casas. Muitos dos moradores se mostravam satisfeitos e curiosos com

1 Edital PROPEX No 004/2016 - Universidade Federal de Campina Grande - UFCG.

20 tesouro enterrado é um mito presente em quase todas as culturas que, no Nordeste, recebe o nome de "botija": "[...] ouro em moedas barras de ouro ou de prata, deixados pelo holandês ou escondido pelos ricos, no milenar e universal costume de evitar o furto ou os ladrões (CÂMARA CASCUDO, 2012). 
a presença dos componentes do projeto que, mesmo náo tendo se dado de maneira abrupta, causou um estranhamento inevitável. Aos poucos, foram notados traços nos rostos, principalmente das crianças, que denunciavam uma felicidade crescente. A cada visita às comunidades, os obstáculos eram sendo reduzidos significativamente; com isto, sucederam duas intervençóes em que a descontração, aprendizado e a possibilidade de fomentar novos diálogos entre universidade e comunidade se deram.

\section{As comunidades remanescentes quilombolas}

O termo quilombo possui profundas raízes coloniais (ALMEIDA, 2002), o que muitas vezes não representa a totalidade fundiária das comunidades designadas como quilombolas no Brasil. É necessário um amplo processo de revisão e descolonização da noção de quilombo, uma vez que essa realidade fundiária não é unívoca. Sobre esses contextos fundiários, Anjos (2009) destaca sete realidades de ocupaçáo do território das comunidades na paisagem social brasileira: 1) ocupação de fazendas falidas e/ou abandonadas; 2) compra de propriedades por escravos alforriados; 3 ) doaçóes de terras para ex-escravos por proprietário de fazendas; 4) pagamento por prestaçóes de serviços em guerras oficiais; 5) terrenos de ordens religiosas deixados para ex-escravos; 6) ocupaçóes de terras no litoral sob controle da Marinha do Brasil; 7) extensão de terrenos da União não devidamente cadastrados. A partir dessa caracterização fundiária, Anjos (2009) apresenta uma tipologia espacial das comunidades quilombolas, que segundo o autor são recorrentes em todo território nacional.

Assim, em concordância com o entendimento da antropologia sobre a questáo, a condição de remanescente de quilombo é também definida de forma dilatada, que enfatiza as identidades dos grupos e o território, buscando evidenciar a interaçáo do meio físico com o grupo social. Portanto, indica a situação presente dos segmentos negros, em diferentes regiốes e contextos, o que é utilizado para designar um legado, uma herança cultural, material e uma forma de organizaçáo política. Isso confere uma referência presencial no sentimento de ser e pertencer a um lugar específico (SCHMITT, 2002) a um grupo cujos membros se reinventam como novos atores sociais, favorecidos pelo art. 68 do Ato das Disposiçóes Constitucionais Transitórias (ADCT), que garante a titularidade das terras.

Deste modo, não se deve imaginar que estes grupos camponeses negros tenham resistido em suas terras até os dias de hoje porque ficaram isolados, à margem da sociedade. Pelo contrário, sempre se relacionaram intensa e assimetricamente com a sociedade brasileira, resistindo a várias formas de violência para permanecer em seus territórios ou, ao menos, em parte deles. Esta realidade também é encontrada na Paraíba.

O território é a chave que aciona a emergência de um sentimento de pertença, fundamental na construção da identidade étnica, os sujeitos se pensam inicialmente como pertencentes a um lugar, onde seus avós, pais e eles mesmo com seus filhos vivem, portanto, um grupo étnico é uma comunidade política-organizacional produzida a partir de certas interaçôes sociais que possuem um caráter dinâmico. Neste contexto de relaçôes onde a etnicidade corresponde à ação dos indivíduos acionada por comportamentos de ordem racional afetiva, a vida cotidiana não é uma simples repetição mecânica, mas o lócus de criação das condiçôes fundamentais para nos tornarmos humanos. 
Ainda nesta relação território/identidade étnica, opera-se a atualização das experiências do passado com os olhos do presente, realizada por uma memória afetiva, onde cada canto, curva, ladeira e grota do território possui uma história imbricada nas histórias de vida de cada sujeito da comunidade. Assim, a terra das comunidades quilombolas do Município de Livramento não é qualquer espaço, é um espaço que se transformou em território pela ação desses sujeitos sintagmáticos que produzem e dão sentido ao mesmo. Ou seja, carregam-no de significados sociais, políticos, históricos e espirituais, portanto, este território ganha uma identidade, não em si mesma, mas na coletividade que nela habita. E tal movimento de produção dessa rede de significados passa pelas histórias contadas de geração em geração, formando uma teia que une tais sujeitos em torno de uma memória comum (SOUZA, 2014).

\section{A contaçáo de histórias}

$\mathrm{O}$ ato de contar histórias é uma das atividades mais antigas de que se tem notícia. Essa arte remonta à época do surgimento do homem há milhóes de anos. Contar histórias e declamar versos constituem práticas da cultura humana que antecedem o desenvolvimento da escrita. Na cultura primitiva, saber ler, escrever e interpretar sinais da natureza era de grande importância, porque mais tarde iam se tornar registros pictográficos, com os quais seriam relatadas coisas do cotidiano que poderia ser lido e compreendido pelos integrantes do grupo.

As histórias são uma maneira mais significativa que a humanidade encontrou para expressar experiências que nas narrativas realistas não acontecem (MATEUS, 2016, p.55). Os contos são temidos porque objetivam os fatos e as verdades que não podem ser expressos pela razáo, por isso, nos estudos dos contos observa-se: "Em primeiro lugar, o fato de que eles falam sempre de relacionamentos humanos primitivos e, por isso, exprimem sentimentos muito arcaicos do psiquismo humano" (VIEIRA, 2005, p. 10).

A contação de histórias é atividade própria de incentivo à imaginação e o trânsito entre o fictício e o real. Ao preparar uma história para ser contada, tomamos a experiência do narrador e de cada personagem como nossa e ampliamos nossa experiência vivencial por meio da narrativa do autor. Os fatos, as cenas e os contextos são do plano do imaginário, mas os sentimentos e as emoçôes transcendem a ficção e se materializam na vida real. (RODRIGUES, 2005, p. 4).

Ademais, é uma atividade fundamental que transmite conhecimentos e valores, e sua atuação é decisiva na formação e no desenvolvimento do processo ensino aprendizagem. Além de pertencer ao campo da educação e à área das ciências humanas, a contação de histórias é uma atividade comunicativa. Por meio dela, os homens repassam costumes, tradiçóes e valores capazes de estimular a formação do cidadão. Por isso, contar histórias é saber criar um ambiente de encantamento, suspense, surpresa e emoção, no qual o enredo e os personagens ganham vida, transformando tanto o narrador como o ouvinte. $\mathrm{O}$ ato de contar histórias deve impregnar todos os sentidos, tocando o coração e enriquecendo a leitura de mundo na trajetória de cada um (MATEUS, 2016, p.56).

Ao considerá-la como portadora de significados para a prática pedagógica, não se restringe o seu papel somente ao entendimento da linguagem. Preserva-se seu 
caráter literário, sua função de despertar a imaginação e sentimentos, assim como suas possibilidades de transcender a palavra (MATEUS, 2016). Nestes termos, as comunidades remanescentes de quilombo, com sua tradição oral, mobilizam este veículo pedagógico nos espaços cotidianos e sinalizam, com isso, a relevância de tais histórias contadas na organização social do grupo.

\section{Métodos}

\section{Registro e contaçáo das histórias orais}

A proposta deste trabalho se insere no cenário de memórias narrativas por meio das contaçôes de histórias, através dos moradores das comunidades quilombolas, buscando de forma sucinta conhecer suas histórias guardadas em lembranças. Todavia, essas cargas de recordação não se limitam apenas ao passado, e sim como uma reconstrução daquilo que passou, as relaçôes destes sujeitos, inseridos em um espaço político, através de suas narrativas, e o seu pertencimento étnico, dando visibilidade às memórias e subjetividades daquele grupo social.

O processo de narrar histórias daquelas comunidades é um ato político, que reforça as relaçooes entre as pessoas e o território, através de uma memória coletiva, formando uma rede ilimitada de subjetividade, de pertencimento àquele lugar. Memória que além de reedificar o pretérito, prepara os sujeitos para uma construção política em todo processo de ocupação do solo, de pertencimento àquele território. Memória como atualizaçáo e luta política, materializadas em narrativas orais.

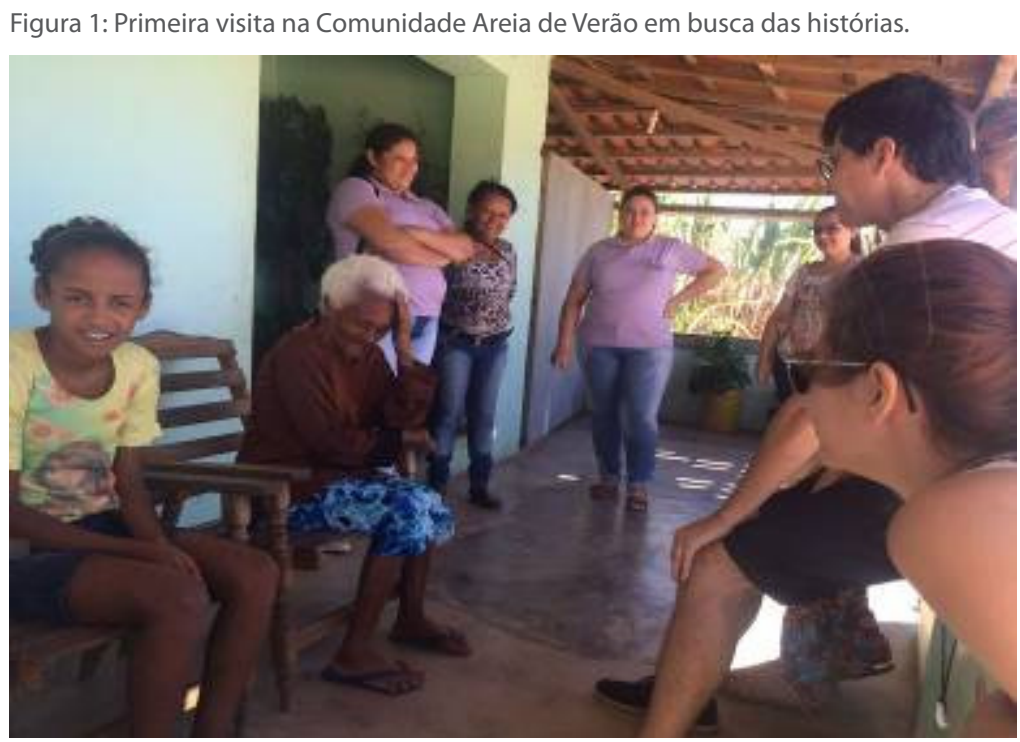

Em maio de 2016, iniciou-se nas comunidades uma busca pelas histórias daqueles quilombos. No início, como em qualquer trabalho, chegar a um lugar onde todas as informações até então eram vagas é desafiador, assim sendo, originou-se a necessidade de fomentar espaços de integraçáo entre a comunidade e a universidade. A contação de histórias foi utilizada como estratégia de aproximação com o campo, para dar visibilidade a uma memória social do grupo, materializada nas narrativas orais. Esta metodologia foi trabalhada pelo grupo da universidade para se tentar alcançar a demanda existente. 
A partir dessa motivação, os moradores das comunidades quilombolas de Livramento foram convidados a participar do evento "A Botija é nossa", de modo que todos os moradores das comunidades se reuniam para ouvir e contar histórias. Os contos são temidos porque objetivam os fatos e as verdades que náo podem ser expressos pela razão, por isso, nos estudos dos contos, observa-se: "Em primeiro lugar, o fato de que eles falam sempre de relacionamentos humanos e, por isso, exprimem sentimentos muito do psiquismo humano" (VIEIRA, 2005), as narrativas míticas têm uma função pedagógica (ELIADE, 2006).

Preserva-se seu caráter literário, sua função de despertar a imaginação e sentimentos, assim como suas possibilidades de transcender a palavra (MATEUS, 2016). Nestes termos, as comunidades remanescentes de quilombo, com sua tradição oral, mobilizam este veículo pedagógico - a contaçáo de histórias, nos espaços cotidianos, e sinalizam a relevância de tais histórias contadas na organizaçáo social do grupo, bem como na construção dos pertencimentos identitários.

Assim, pode-se salientar que a identidade enquanto conceito pode ser compreendida em dois planos distintos: o interno, que consiste na percepçáo de si como membro de uma comunidade; e o externo, que corresponde ao reconhecimento desse pertencimento como identidade social.

\section{A oralidade e memória na comunidade}

A oralidade em sociedades como a brasileira também é fundamental e adquire vários sentidos, pois constitui as interaçóes das pessoas com o mundo e com o outro. É por meio da palavra falada e dirigida a elas por sujeitos mais experientes, desde o nascimento, que estabelecem laços, interagem, inserem-se e se apropriam da cultura.

Trabalhar com a oralidade de memória nas comunidades quilombolas é rebuscar no passado afetividades entre o povo e o território, fomentando debates de caráter político e étnico. Implica que todos os membros possam, de forma categórica, considerarem-se sujeitos sociais e de direitos, que sua trajetória política vem de um povo que teve sua liberdade ceifada, que aquele solo que ocupam vai além de lotes, onde seu passado está vivo e dinâmico. $\mathrm{O}$ projeto de extensão se propôs a contribuir para a construção e fortificação de uma identidade étnica daqueles quilombolas, onde suas subjetividades de lutas históricas pudessem ser compreendidas, respeitadas e tratadas como tal.

\section{Seleçáo das histórias a serem contadas}

Partindo das literaturas de origem africana - narrativas orais da comunidade - foram selecionadas algumas histórias, após algumas visitas e em conversa com os moradores, o grupo obteve conhecimento das mesmas.

Neste sentido, tanto a contação como o registro das histórias orais assumidas neste projeto como instrumentos metodológicos possibilitaram a percepção/experiência com as dinâmicas de organização desse grupo étnico (regras morais, as interdiçôes, as estratégias de sobrevivências, as experiências espirituais, dentre outras), na medida em que tais histórias possuem um sentido pedagógico, portanto, formativo. 
Figura 2: Seleção das histórias.

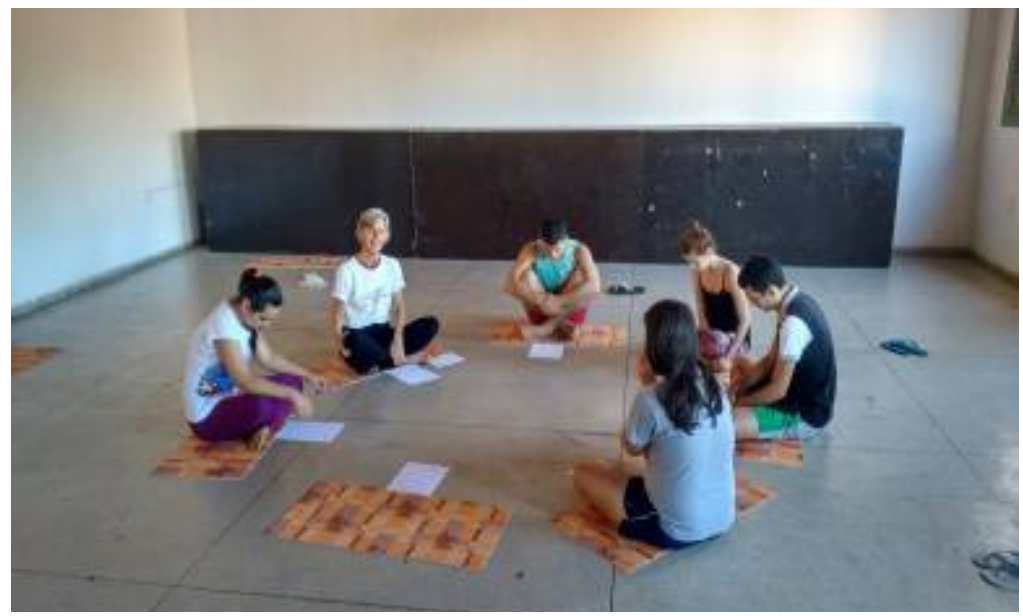

Ainda, suscitar o imaginário, encontrar e criar novas ideias, estimular o intelecto, descobrir o mundo imenso dos conflitos, das dificuldades, dos impasses, das soluçóes. É ouvindo histórias que se podem sentir emoçóes e viver profundamente tudo o que as narrativas provocam em quem as ouve ou as lê, com toda a significância e verdade que cada uma delas faz ou não brotar.

\section{Oficina leituras de texto dramáticos}

$\mathrm{Na}$ oficina de leitura de textos dramáticos, foi apresentado o gênero teatral, sua história de origem, elementos de sua composição, narrativas, além de vários modos do agir em cena. Posteriormente, foram postas em prática encenaçōes feitas pelos extensionistas, como modo de exercitar a junção de conceitos, como contar a mesma história de diferentes modos e propor diferentes abordagens nas apresentaçóes a serem feitas.

Foram desenvolvidos debates sobre métodos de interação com o público infantil, haja vista que existem dificuldades para que esse público esteja atento aos pontos abordados nas exposiçóes. Mateus (2016) trata da importância da contaçáo de histórias como prática educativa na educação infantil. Neste sentido, incitar a imaginação, como método, permite que o ser humano crie habilidades de entendimento e compreensão de histórias de ficção, sendo o ser empírico entendido dentro das narrativas.

Figura 3 Interação com público infantil

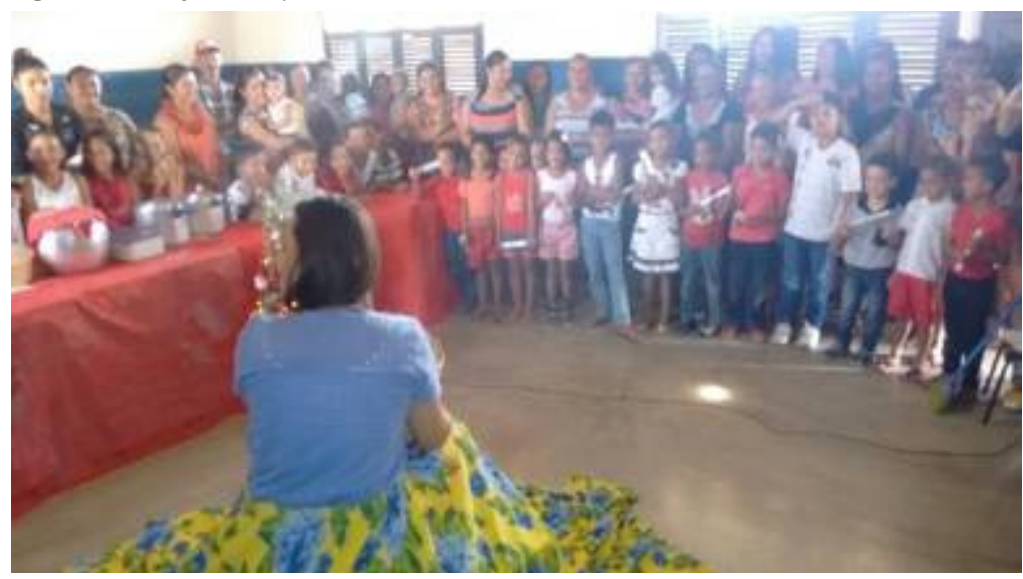


Com a leitura dramatizada bem feita e bem conduzida, pode-se conquistar o leitor e transformá-lo num espectador inveterado, mas mesmo sem se tornar um espectador, ele passará por todas as emoçóes que um espectador passa ao ver o texto encenado. Quando bem feita, essa leitura é capaz de ser tão prazerosa quanto um espetáculo, guardadas as suas respectivas origens, diferenças e similaridades - literatura dramática e teatro.

Figura 4: Oficina de leitura texto dramático

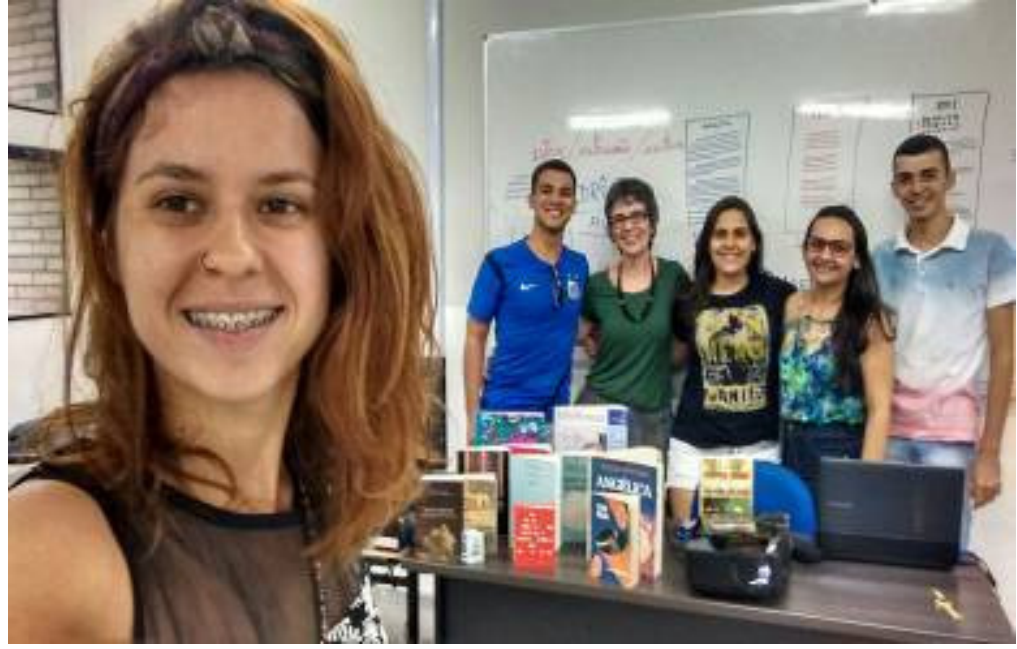

\section{Intervençóes poético-musicais}

Para iniciar a compreensão de alguns dos recursos utilizados na contação de histórias, nada melhor que observar esses elementos na música. Por ser também um texto poético, ela nos possibilita explorar muitos aspectos, para que todos compreendam de forma prazerosa. Partindo dos recursos poéticos e musicais, foi realizada na comunidade uma apresentação intitulada "A menina e sua saia mágica". Nessa apresentaçáo da contação, a música e a dança entram dando características à apresentaçáa, e através disso, movimento e dramatizaçáo, sendo de fundamental importância na contação.

Figura 5: A menina e sua saia mágica

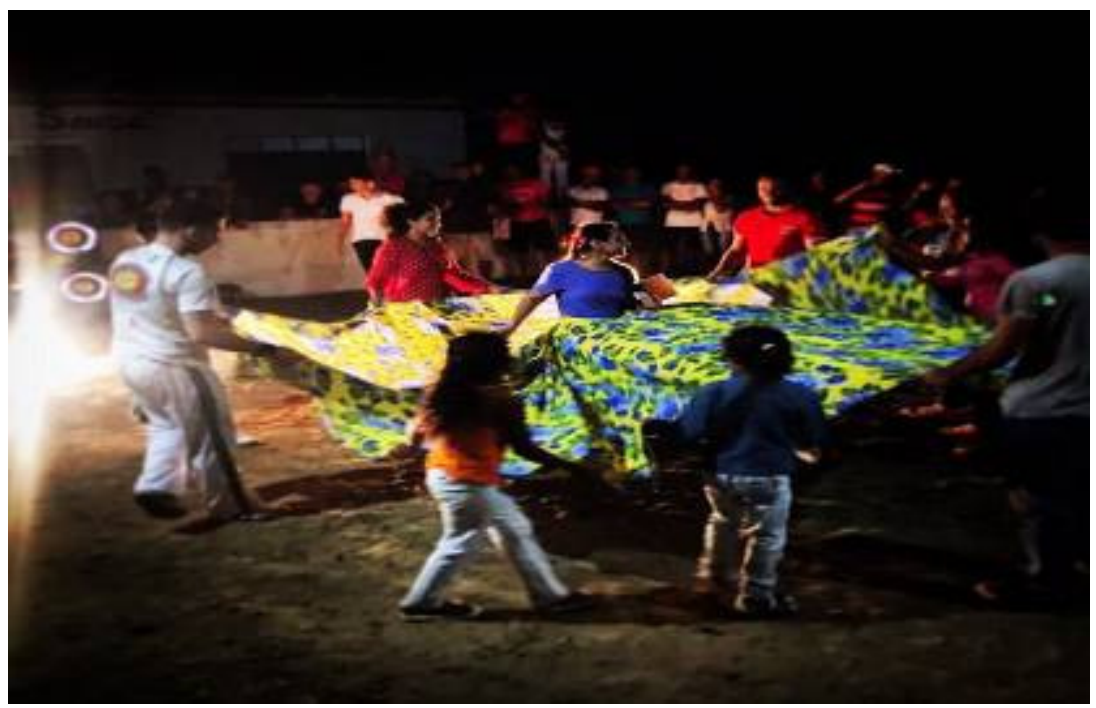


Figura 6: Participação dos membros das comunidades nas apresentações.

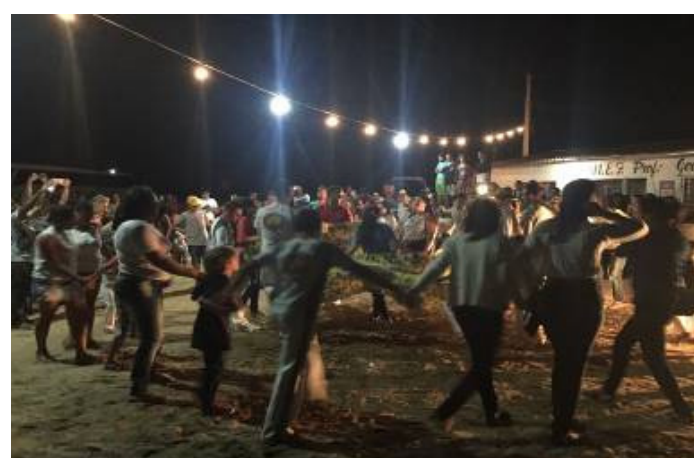

Figura 7: Apresentação artística

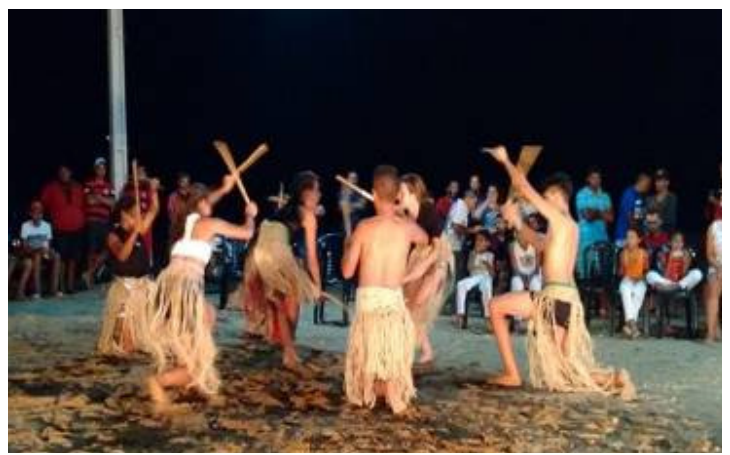

\section{Resultados}

Após as intervenções realizadas, o processo de aproximação com as comunidades segue em progresso, criando novas pontes e questóes a serem discutidas como instrumentos de consolidação da pesquisa. Trabalhar com contação de histórias deu o real protagonismo àqueles que ocupam um território tradicional, que segue em dinamismo, quebrando o paradigma de visão de isolamento social destes que compóem as comunidades.

É notória a satisfaçáo dos sujeitos da comunidade para com as propostas que foram construídas mutualmente em campo. O processo de integração entre universidade e comunidades tradicionais se deu de forma satisfatória para ambas as partes. Trabalhar com contação de histórias, utilizando a categoria mito como catalizador do processo de socialização e de afirmação de sujeitos quilombolas, é dar o real protagonismo àqueles que ocupam um território tradicional, que segue em dinamismo, quebrando o paradigma de visão de isolamento social destes que compóem as comunidades.

Figura 8: Integrantes do grupo, com alguns representantes da comunidade e colaboradores do projeto.

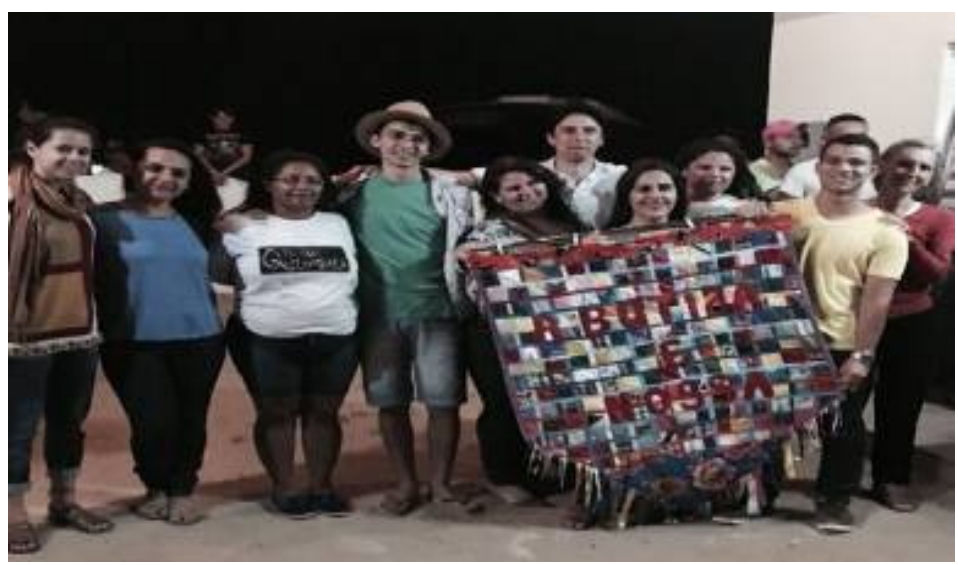

\section{Conclusão}

As atividades realizadas neste projeto têm contribuído para estreitar os laços entre as comunidades e a universidade. Os sujeitos pertencentes aos grupos quilombolas foram de fundamental importância para o desenvolvimento e êxito as atividades. Desde modo, 
todas as intervençóes nos proporcionaram experiências riquíssimas, que foram adquiridas a partir das ações pedagógicas, podendo-se desenvolver o real sentido do projeto, com alusão à contação de histórias, descobertas e resgatadas pelos moradores. A cada visita, sentimos pelo semblante, o olhar, o sorriso, a alegria, que éramos acolhidos, e a satisfação era de todos, o que facilitou a troca de aprendizados e ampliou os conhecimentos, do professor aos alunos, colaboradores, e todos que fizeram parte do projeto, diretamente e indiretamente.

\section{Referências}

ABRAMOVICH, Fanny. Literatura infantil: gostosuras e bobices. São Paulo: Scipione, 1989.

ALMEIDA, Alfredo Wagner Berno de. Os Quilombos e a Novas Etnias. In: O'DWYER, Eliane Cantarino (Org.). Quilombos: identidade étnica e territorialidade. Rio de Janeiro - RJ: Ed. FGV/Associação Brasileira de Antropologia-ABA, 2002. p. 43-81.

ANJOS, Rafael Sanzio Araújo. Quilombos: geografia africana, cartografia étnica, territórios tradicionais. Brasília - DF: Mapas Editora \& Consultoria, 2009.

CÂMARA CASCUDO, Luís da. Dicionário do Folclore Brasileiro. São Paulo: Global, 2012.

ELIADE, Mircea. Mito e realidade. São Paulo-SP: Perspectiva, 2006.

MATEUS, Ana do Nascimento Biluca et al. A importância da contação de história como prática educativa na educação infantil. Disponível em: http://periodicos.pucminas.br/index.php/pedagogiacao/article/ viewFile/8477/7227. Acesso em: 02/02/2016.

RODRIGUES, Edvânia Braz Teixeira. Cultura, arte e contação de histórias. Goiânia, 2005.

SCHMITT, Alessandra; TURATTI, Maria Cecília Manzoli; CARVALHO, Maria Celina Pereira de. A atualização do conceito de quilombo: Identidade e Território nas definições teóricas. Ambiente \& Sociedade. Ano V, n.10, set/2002.

SOUZA, Wallace G. Ferreira de. Famílias, Território e Espiritualidades: uma etnocartografia de Caiana dos Crioulos-PB. Tese (Doutorado em Ciências Sociais) - Universidade Federal de Campina Grande-UFCG, Campina Grande, 2014.

VANSINA, J. A tradição oral e sua metodologia. In: KI ZERBO, J. História geral da África, v. 1: Metodologia e pré-história da África. Brasília: UNESCO, MEC, UFSCar, 2010. p. 139-166.

VIEIRA, Isabel Maria de Carvalho. O papel dos contos de fadas na construção do imaginário infantil. Revista criança- do professor de educação infantil, v. 38, p. 10, 2005.

Artigo recebido em: $30 / 01 / 2017$

Aceito para publicaçăo em: 23/03/2017 